Article

\title{
Predicting the Chlorophyll Content of Maize over Phenotyping as a Proxy for Crop Health in Smallholder Farming Systems
}

\author{
Kiara Brewer ${ }^{1, *}$, Alistair Clulow ${ }^{1}$, Mbulisi Sibanda ${ }^{2} \mathbb{D}$, Shaeden Gokool ${ }^{3} \mathbb{D}$, Vivek Naiken ${ }^{1}$ and \\ Tafadzwanashe Mabhaudhi ${ }^{4,5}$ (D)
}

1 Discipline of Agrometeorology, School of Agricultural, Earth and Environmental Sciences, University of KwaZulu-Natal, Pietermaritzburg 3209, South Africa; clulowa@ukzn.ac.za (A.C.); naikenv@ukzn.ac.za (V.N.)

2 Department of Geography, Environmental Studies \& Tourism, Faculty of Arts, University of the Western Cape, Bellville, Cape Town 7535, South Africa; msibanda@uwc.ac.za

3 Centre for Water Resources Research, School of Agricultural, Earth and Environmental Science, University of KwaZulu-Natal, Pietermaritzburg 3209, South Africa; GokoolS@ukzn.ac.za

4 Centre for Transformative Agricultural and Food System, School of Agricultural, Earth and Environmental Science, University of KwaZulu-Natal, Pietermaritzburg 3209, South Africa; mabhaudhi@ukzn.ac.za or t.mabhaudhi@cgiar.org

5 International Water Management Institute (IWMI-GH), West Africa Office, PMB CT 112 Cantonments, Accra GA015, Ghana

* Correspondence: 216012945@stu.ukzn.ac.za

\section{check for}

updates

Citation: Brewer, K.; Clulow, A.; Sibanda, M.; Gokool, S.; Naiken, V.; Mabhaudhi, T. Predicting the Chlorophyll Content of Maize over Phenotyping as a Proxy for Crop Health in Smallholder Farming Systems. Remote Sens. 2022, 14, 518. https://doi.org/10.3390/rs14030518

Academic Editors: Mi Wang, Hanwen Yu, Jianlai Chen and Ying Zhu

Received: 16 November 2021

Accepted: 17 January 2022

Published: 21 January 2022

Publisher's Note: MDPI stays neutral with regard to jurisdictional claims in published maps and institutional affiliations.

Copyright: (c) 2022 by the authors Licensee MDPI, Basel, Switzerland. This article is an open access article distributed under the terms and conditions of the Creative Commons Attribution (CC BY) license (https:// creativecommons.org/licenses/by/ $4.0 /)$.

\begin{abstract}
Smallholder farmers depend on healthy and productive crop yields to sustain their socioeconomic status and ensure livelihood security. Advances in South African precision agriculture in the form of unmanned aerial vehicles (UAVs) provide spatially explicit near-real-time information that can be used to assess crop dynamics and inform smallholder farmers. The use of UAVs with remotesensing techniques allows for the acquisition of high spatial resolution data at various spatio-temporal planes, which is particularly useful at the scale of fields and farms. Specifically, crop chlorophyll content is assessed as it is one of the best known and reliable indicators of crop health, due to its biophysical pigment and biochemical processes that indicate plant productivity. In this regard, the study evaluated the utility of multispectral UAV imagery using the random forest machine learning algorithm to estimate the chlorophyll content of maize through the various growth stages. The results showed that the near-infrared and red-edge wavelength bands and vegetation indices derived from these wavelengths were essential for estimating chlorophyll content during the phenotyping of maize. Furthermore, the random forest model optimally estimated the chlorophyll content of maize over the various phenological stages. Particularly, maize chlorophyll was best predicted during the early reproductive, late vegetative, and early vegetative growth stages to RMSE accuracies of $40.4 \mu \mathrm{mol} / \mathrm{m}^{-2}, 39 \mu \mathrm{mol} / \mathrm{m}^{-2}$, and $61.6 \mu \mathrm{mol} / \mathrm{m}^{-2}$, respectively. The least accurate chlorophyll content results were predicted during the mid-reproductive and late reproductive growth stages to RMSE accuracies of $66.6 \mu \mathrm{mol} / \mathrm{m}^{-2}$ and $69.6 \mu \mathrm{mol} / \mathrm{m}^{-2}$, respectively, as a consequence of a hailstorm. A resultant chlorophyll variation map of the maize growth stages captured the spatial heterogeneity of chlorophyll within the maize field. Therefore, the study's findings demonstrate that the use of remotely sensed UAV imagery with a robust machine algorithm is a critical tool to support the decision-making and management in smallholder farms.
\end{abstract}

Keywords: chlorophyll; drones; machine learning; precision agriculture; random forest; smallholder farming systems; UAV applications; unmanned aerial vehicle

\section{Introduction}

Smallholder agricultural systems contribute significantly to developing nations' agricultural production, livelihood sustenance, and socio-economic growth [1]. Specifically, in sub-Saharan Africa, smallholder farming practices are threatened by a decline in productivity and profitability due to climatic variability [2-4]. Maize (Zea mays L.) is one of 
the staple grain crops grown in South Africa and is extensively cultivated at a subsistence scale for household economic gain, food security, and feedlots [3,5]. Smallholder farmers typically cultivate maize under rainfed conditions, maximizing production and producing healthy crop yields. Despite the goals of smallholder farmers to optimize yields, small-scale farming systems often face a variety of challenges $[3,6]$. Their dependence on rainfall poses a significant threat to crop yields, as reduced seasonal rainfall and severe weather phenomena impact crop health, biochemical processes, and physical development $[7,8]$. Smallholder farms also lack the resources required to maximize their potential and are often faced with low unproductive yields that are significantly lower than the potential of the land [9]. Hence, it is imperative to provide smallholder farmers with innovative, effective, low-cost solutions to optimize their productivity to produce increased and healthy yields [10,11]. Therefore, a deeper understanding of crop dynamics could assist smallholder farmers in identifying crop-health issues at an early stage, allowing them to implement the necessary remedial solutions to ensure productivity.

Literature has documented various indicators of crop health [12-14]. For example, previous studies have used soil quality [15], nitrogen levels [16], crop yield [17], and microorganisms [18] as indicators of plant health and productivity. However, this study uses chlorophyll content as an indicator of crop health, as it has been identified as one of the most important and reliable health and productivity indicators $[12,19,20]$. This is due to the leaf's biophysical pigment and biochemical photosynthetic processes that suggest plant productivity [21,22]. Additionally, literature has documented successful studies using chlorophyll to measure plant health and productivity [20,23-25]. Hence, monitoring chlorophyll concentration and variability in plants could aid smallholder farmers in evaluating crop productivity through time [26], which is significant towards detecting subtle crop changes and optimizing healthy yields in smallholder farming practices $[27,28]$.

Advanced and objective tools such as remote sensing have been utilized to estimate and monitor agricultural vegetative health and productivity for many years [29,30]. For example, Sibanda et al. [31] estimated the foliar chlorophyll content of grasses using fieldbased hyperspectral data, Delegido et al. [32] estimated the chlorophyll content of multiple crops using Sentinel-2 red-edge bands, and Kooistra and Clevers [33] estimated the chlorophyll content in potato leaves using vegetation indices derived from RapidEye satellite imagery. Such studies have demonstrated the utility of remote sensing as a powerful tool in characterizing chlorophyll concentrations in different vegetation. Thus, at a farm scale, it may be useful to use chlorophyll as a proxy for crop health and productivity [34].

Remote-sensing techniques obtain the ability to monitor crop productivity and map its spatial distribution based on high-resolution images of varied wavelengths [10,35,36]. Previous conventional applications of earth observation techniques use satellite-borne earth observation or manned aerial vehicles $[37,38]$. However, a major limitation of freely available satellite-borne data is its inability to fulfill the ever-increasing need for high spatial and temporal resolution data, which is necessary for monitoring small-scale crop properties throughout phenotyping [39]. Previous studies have recommended higher spatio-temporal resolutions when evaluating small-scale farms for improved outputs [40-43]. Therefore, manned aerial vehicles can overcome the issues of spatio-temporal resolution, but the associated costs are a major limitation to smallholder farms.

In recent years, unmanned aerial vehicles (UAVs), commonly known as drones, have been globally recognized as an innovative, low-cost, and effective precision technology for agricultural applications. UAVs offer advanced image data throughput analytics at very high resolutions (VHR) and have proven to be effective in overcoming the limitations of satellite imagery $[10,44]$. UAVs have great potential in small-scale agriculture as the low-flying altitudes capture VHR spatial and spectral data. Multispectral cameras acquire high-resolution images mounted onboard UAVs, which offer near-real-time data that are critical for monitoring subtle changes in crop phenology and crop health. Moreover, UAVs can be deployed repeatedly at user-determined ground-sampling distances and revisit times, which is impossible with conventional freely accessible satellite-borne sensors such 
as Landsat 8 Operational Land Imager (OLI) or Sentinel 2 MSI [45]. Thus, VHR UAV imagery can detect individual maize plants, canopy patches and ultimately, phenological growth patterns over the fragmented smallholder fields. Most of the studies that have evaluated the utilization of UAVs in crop phenology and crop health have been conducted in experimental plots [46-48]. Therefore, accurate mapping and analysis of smallholder maize fields using a VHR UAV hold significant potential for providing data that could inform farmers on the health status of their crops through the phenological cycle.

Specifically, multispectral chlorophyll data can be optimally assessed using UAVderived vegetation indices (VIs) and a robust machine-learning algorithm. VIs are mathematical transformations of image bands used quantitatively to extract spectral properties such as vegetation cover, plant vigor and growth dynamics $[49,50]$. The most common index used for crop health is the normalized difference vegetation index (NDVI), which is directly used to provide information on the physiological health status of crops and crop-growth changes [51,52]. Particularly, chlorophyll-specific VIs have proven to be more valuable than normalized VIs in some instances as they include a variety of combinations from bands that reflect highly in vegetation [29]. Such indices include the canopy chlorophyll content index (CCCI) and the modified chlorophyll absorption ratio index (MCARI), green normalized difference vegetation index (GNDVI), and green chlorophyll index (CIgreen), which have shown significant correlations to crop chlorophyll content [53-56]. Furthermore, machine learning algorithms such as random forest, support vector machines, and multiple linear regressions have proven to be instrumental in characterizing crop chlorophyll content and health status [57-60]. The random forest ensemble has been widely proven to outperform the other two aforementioned algorithms [61,62]. Hence it is anticipated that the combination of UAV-derived VIs and the robust random forest regression could produce accurate results to quantitatively assess chlorophyll content of maize as an indicator of health in smallholder farms.

Thus, with maize being one of the dominant food crops grown across Southern Africa, there is a need to assess its health in smallholder agricultural systems through a robust multispectral sensor. A multispectral sensor enables proximal remote-sensing analysis of maize and can potentially predict chlorophyll content, which serves as an informant on the health status of the crop. However, to the best of our knowledge, very few studies have sought to evaluate the prospects of UAV-derived remotely sensed data in assessing crop health in smallholder croplands. This is primarily because rural smallholder farms are fragmented and small in size, while a large number of the rural folks are dependent on the higher revenues they receive from the sale of their maize yields that appear healthier and display more vigorous chlorophyll concentrations. In this regard, this study investigates the potential of multispectral UAV imagery to assess maize-crop chlorophyll content using the random forest model simulation for an improved understanding of crop health and productivity in smallholder farming systems. Specifically, the study used a UAV for image acquisition, stationary spectral reflectance sensors (SRS) to measure NDVI, and a soil plant analysis development (SPAD) device to measure the foliar chlorophyll of specific maize crops. These measurements all contributed to testing the utility of the UAV multispectral data. The specific objectives of the study were to: (1) estimate chlorophyll content variations across the different maize phenological stages using UAV-derived data, (2) determine the optimal maize growth stage(s) for chlorophyll model prediction.

\section{Materials and Methods}

\subsection{Study Site Description}

The research was conducted over 4 months from February 2021 to May 2021 in the rural area of Swayimani, KwaZulu-Natal $\left(29^{\circ} 31^{\prime} 24^{\prime \prime}\right.$ S; $\left.30^{\circ} 41^{\prime} 37^{\prime \prime} \mathrm{E}\right)$. Swayimani is in the uMshwathi Local Municipality and is located approximately $55 \mathrm{~km}$ north-east of Pietermaritzburg. The small, communal area covers a geographical extent of approximately $36 \mathrm{~km}^{2}$, and land use is dominated by smallholder farming systems of the local community. Common crops cultivated in the area include white and yellow maize, sugarcane, amadumbe 
(taro), and sweet potato. The smallholder farmers follow traditional farming methods of planting, maintenance, and manual harvesting of crops. Farm plots are rainfed, fertilized using livestock manure and hand-weeded by farmers. Alternatively, the small growers use herbicide backpack sprayers to control weeds and grasses. The area is predominantly characterized by smallholder farming, regarded as food security and livelihood sustenance. The produce is sold at local markets for economic benefits, sustaining farmers' livelihoods.

Agriculture and crop production in Swayimani is supported by the favorable environmental conditions of the region. The climate is characterized by warm wet summers and cool dry winters, with an annual average air temperature of approximately $18{ }^{\circ} \mathrm{C}$. The mean annual rainfall ranges from 600 to $1200 \mathrm{~mm}$, with the majority of rain occurring during the summer in the form of thunderstorms. During the research period, Swayimani had a maximum average air temperature of $24{ }^{\circ} \mathrm{C}$ and total rainfall of $242.8 \mathrm{~mm}$ amongst other weather data (Figure 1). Weather conditions were continuously monitored by the Automatic Weather Station installed at a Swayimani high school. Weather data were downloaded from the Swayimani weather website. The weather station is situated approximately $2 \mathrm{~km}$ from the smallholder maize farm, and as such, it is proximally adequate in capturing the weather conditions of the study site. The research was conducted on a smallholder maize field of $30 \times 96\left(2850 \mathrm{~m}^{2}\right)$ (Figure 2). The field was located on a slope that reached an elevation of approximately $850 \mathrm{~m}$ to $839 \mathrm{~m}$.

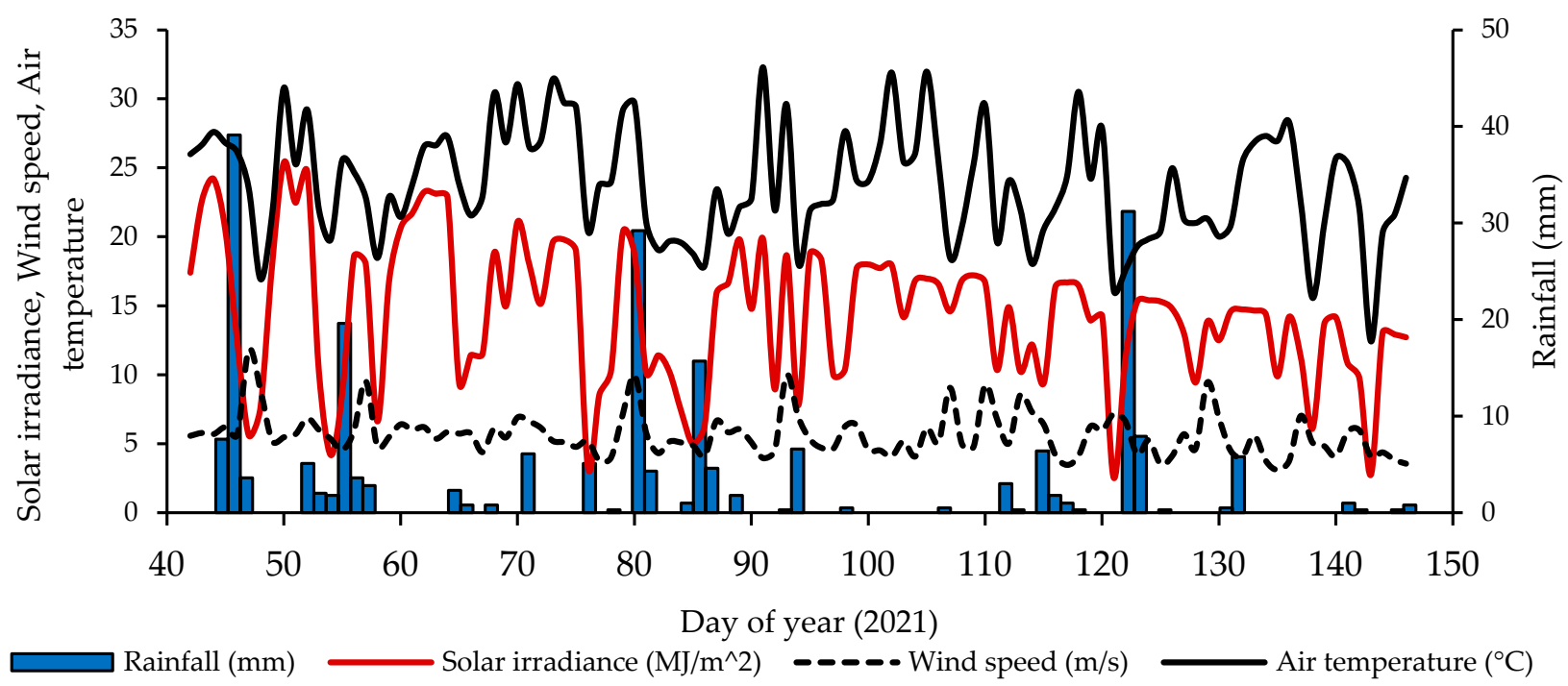

Figure 1. Swayimani weather conditions over the period of maize phenotyping.

\subsection{Maize Phenotyping}

Maize seedlings were sown on the 8 February 2021 and harvested on the 26 May 2021 (Table 1), having a total growth cycle of 108 days. Chlorophyll was examined at different growth stages of the maize phenological cycle. Maize phenology is generally divided into vegetative stages (which range from emergence to tasseling according to the number of fully expanded leaves) and reproductive stages (which range from silking to physiological maturity according to the degree of kernel development) $[63,64]$. Certain transitions are important for monitoring and informing smallholder farmers within the various stages, these being crop vegetative emergence (date of onset photosynthetic activity, termed VE), tasseling (date when maximum leaf area is attained and maize tassels emerge, termed VT), initiation of senescence (date when green leaf area visibly begins to decrease) [65]. 

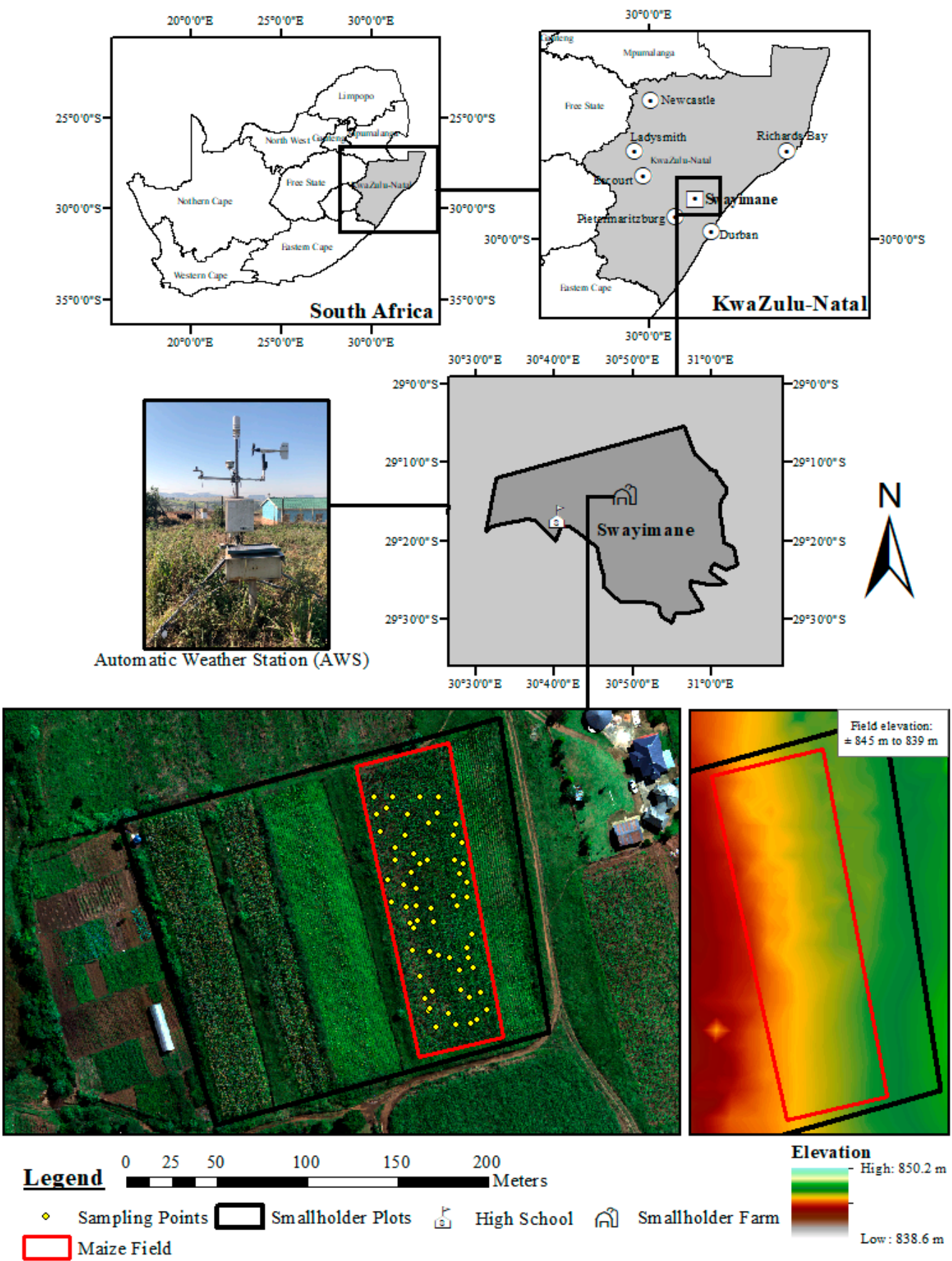

Figure 2. Location of the Swayimani study area, study site, and smallholder maize field.

It is worth mentioning that during the mid-vegetative stage, the field's western portion (lower elevation) appeared unhealthy. This may have been because this portion of the field was not weeded during the early vegetative growth stage with the rest of the field. However, the farmer applied herbicide during the mid-vegetative growth stage to remove grasses and weeds found between maize rows. Consequently, the herbicide impacted these crops' health status, and the maize suffered herbicide burn. 
Table 1. Maize growth stages.

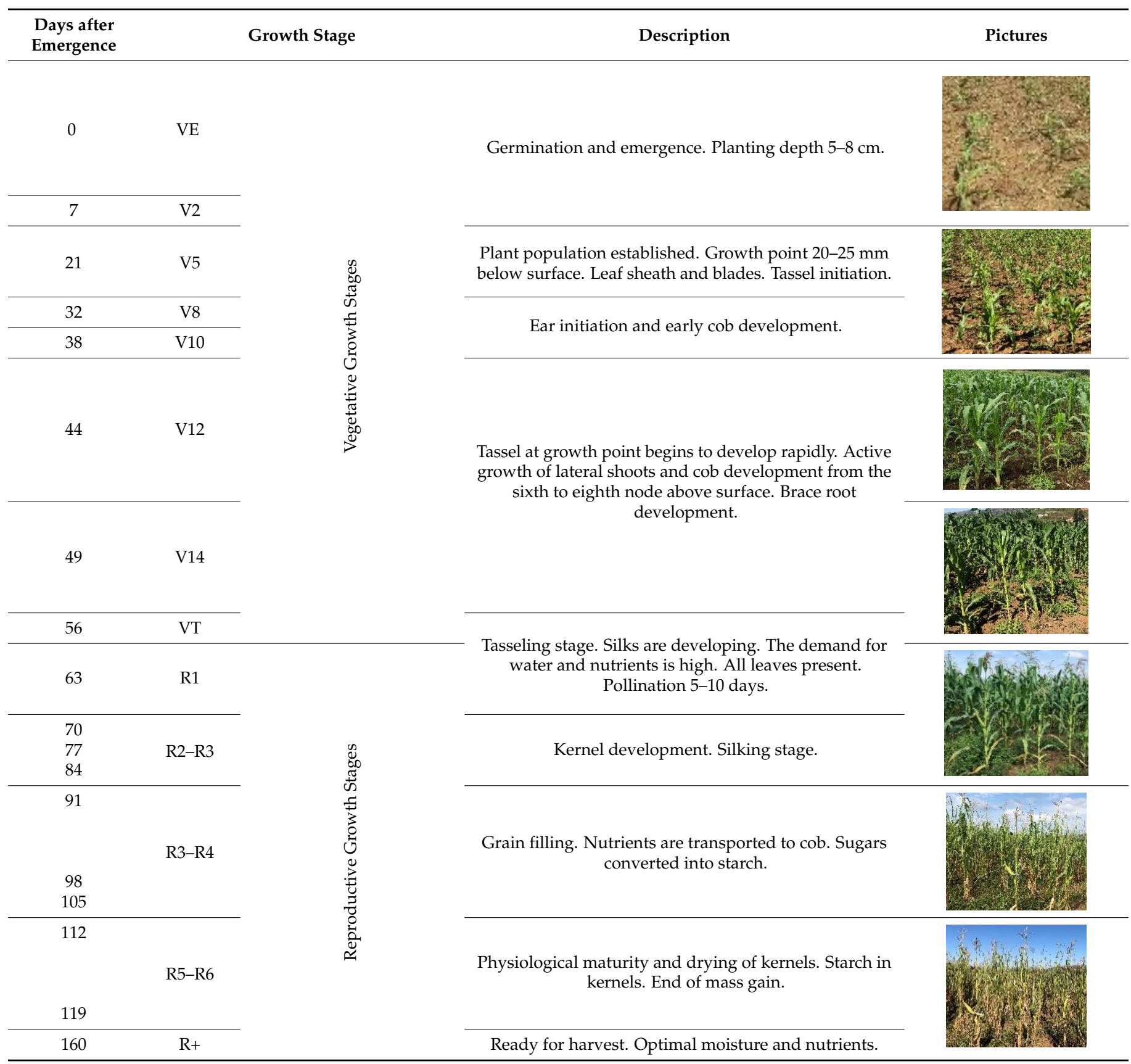

\subsection{Field Data Collection, Sampling, and Survey}

Field data collection was conducted throughout the maize phenological cycle.

In-field chlorophyll measurements of maize, at 2-week intervals, were collected from the early vegetative (V5) growth stage to the late reproductive growth stages (R6). Presampling of the maize smallholder field was conducted in Google Earth Pro, where the experimental field's polygon was digitized. The digitized polygon was then imported into ArcGIS 10.5, where it was used to generate sampling points. A total of 63 sample points were generated based on stratified random sampling within the digitized field boundary. These points were then uploaded into a handheld Trimble Global Positioning System (GPS) with submeter accuracy $(1-100 \mathrm{~cm})$. These locations were used to navigate to each sample point for field data collection. The maize plants at each sampling point were marked for consistent biweekly measurement. 
A Konica Minolta soil plant analysis development (SPAD) 502 chlorophyll meter (Minolta corporation, Ltd., Osaka, Japan) was used to measure the chlorophyll content of maize leaves. SPAD meter readings are portable, nondestructive measurements of the red $(650 \mathrm{~nm})$ and infrared $(940 \mathrm{~nm})$ radiation leaf transmittance. The device instantly calculates a SPAD value corresponding to the chlorophyll concentration in the sample leaf by providing a unitless SPAD value [31,66]. Field measurements were conducted between 10:00 a.m. to 2:00 p.m., corresponding with the optimal period of the day for crop photosynthetic activity. During the early growth stages (where a six-leaf was present), the SPAD readings were measured on the newest fully expanded leaf with an exposed collar (width $>7 \mathrm{~cm}$ ). After the tasseling stage, the ear leaf (i.e., the leaf attached at the same node as the primary ear shank) was measured [67]. Readings were taken on one leaf per plant. The different locations of leaf measurement included: (a) the midpoint of each leaf blade, next to the main leaf vein, (b) approximately $2 / 3$ down from the leaf tip, and (c) approximately $1 / 3$ of the way down from the leaf tip. An average of the three measurements per leaf was recorded to reduce the location precision issues. Most of the leaves that were considered for this procedure were big (greater than $7 \mathrm{~cm}$ ) and exposed to sunlight and the camera. In this regard, it is suggested that future studies should consider using GPS gadgets with up to a cm accuracy in measuring the sampling points. The chlorophyll meter was sheltered from direct sunlight when conducting the chlorophyll readings. SPAD meter readings were conducted at the same time as UAV image acquisition. Subsequently, SPAD values were transformed into chlorophyll-based values using Equation (1) derived by Markwell et al. [68] that achieved an $R^{2}=0.94$ :

$$
C h l=10^{\left(M^{0.264}\right)}
$$

where Chl represents the total chlorophyll-per-unit leaf area in $\mu \mathrm{mol} / \mathrm{m}^{-2}$ and $M$ is the unitless SPAD value [69]. The chlorophyll data were then added to the 63-sampling points map in a geographical information system (GIS). The point map was overlaid with the multispectral UAV image of each sampling point's derived spectral reflectance values.

\subsection{UAV Multispectral-Thermal Camera and Platform}

The DJI Matrice 300 (DJI M-300) platform mounted with a MicaSense Altum camera and Downwelling Light Sensor 2 (DLS-2) was used to conduct aerial-based flights over the smallholder farms. The rotary-wing DJI M-300 series has vertical takeoff and landing (VTOL) technology, making it well-suited for small-scale agricultural crop imaging (Figure 3a). The DJI M-300 platform novelties include its $15 \mathrm{~km}$ transmission range, $7000 \mathrm{~m}$ maximum altitude, obstacle avoidance, flight-path planning and locational position tracker. The maximum flight time of the M-300 is $55 \mathrm{~min}$ (without payload), and it can reach a maximum speed of $27 \mathrm{~m} / \mathrm{s}$, which surpasses most drone platforms on the market. Moreover, the MicaSense Altum camera is a multispectral and thermal-imaging sensor that integrates five spectral high-resolution narrow bands (blue, green, red, red-edge, near-infrared) with a radiometric longwave infrared thermal camera (Figure 3b). The high-performance camera offers synchronized multispectral and thermal-image capture and uses a global shutter that supports a 1-s capture rate for crisp and aligned imagery [70]. The multispectral bands have a sensor resolution of $2064 \times 1544$ at $120 \mathrm{~m}$ (3.2 megapixels per multispectral band) and a ground sample distance (GSD) of $5.2 \mathrm{~cm}$ per pixel at the height of $120 \mathrm{~m}$, suggesting the optimum flight altitude above the crop to receive high-resolution images (Table 2). The camera also has a $48^{\circ} \times 37^{\circ} \mathrm{FOV}$, with an $8 \mathrm{~mm}$ focal length. 


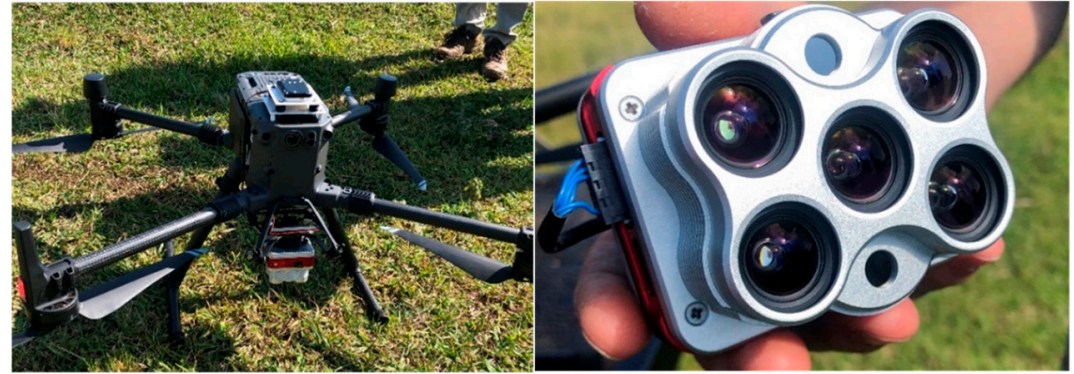

(a)

(b)

Figure 3. (a) DJI Matrice 300 platform, and (b) MicaSense Altum multispectral-thermal camera.

Table 2. MicaSense Altum camera specifications.

\begin{tabular}{cccc}
\hline Band & Spectral Color & Band Center/Range & $\begin{array}{c}\text { Ground Sampling Distance at a } \\
\text { Flying Height of 120 } \mathbf{~}\end{array}$ \\
\hline 1 & Blue & $475 \mathrm{~nm}$ & $5.2 \mathrm{~cm}$ per pixel \\
2 & Green & $560 \mathrm{~nm}$ & $5.2 \mathrm{~cm}$ per pixel \\
3 & Red & $668 \mathrm{~nm}$ & $5.2 \mathrm{~cm}$ per pixel \\
4 & Red-edge & $717 \mathrm{~nm}$ & $5.2 \mathrm{~cm}$ per pixel \\
5 & Near-infrared & $842 \mathrm{~nm}$ & $5.2 \mathrm{~cm}$ per pixel \\
6 & Thermal infrared & $8000-14,000 \mathrm{~nm}$ & $5.2 \mathrm{~cm}$ per pixel \\
\hline
\end{tabular}

\subsection{Image Acquisition and Processing}

A shapefile of the maize field was digitized in Google Earth Pro and imported into the DJI M-300 smart console, where it was used to design a flight plan covering the study area (Figure 4a). The flight plan enabled a hands-free drone flight mission over the study field and adjacent areas. The UAV was calibrated before and after the flight using the MicaSense Altum calibrated reflectance panel (CRP). This included the user manually taking an unshaded image directly over the CRP to discern the lighting conditions of the specific flight date, time, and location (Figure $4 b$ ). We conducted UAV flights every 2 weeks on selected days with clear sky conditions. UAV flights were conducted between 10:00 a.m. and 12:00 p.m., which is the time of optimal solar irradiance. This period also coincided with chlorophyll content measurements. Detailed flight conditions are presented in Table 3.

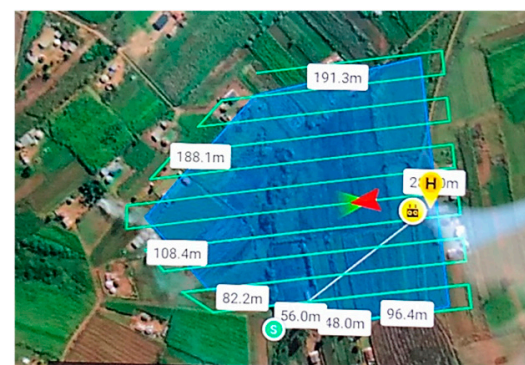

(a)

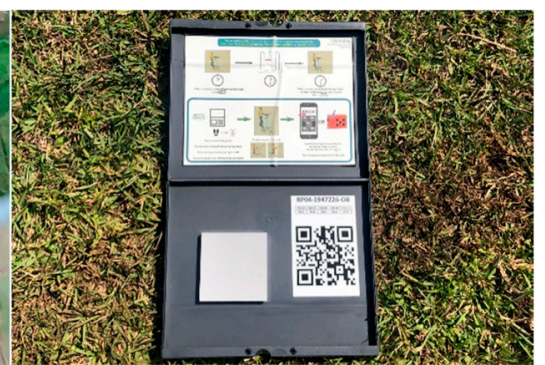

(b)

Figure 4. (a) DJI M-300 flight plan, (b) MicaSense Altum calibration reflectance panel.

Table 3. UAV flight specifications.

\begin{tabular}{cc}
\hline Parameters & Specifications \\
\hline Altitude & $100 \mathrm{~m}$ \\
Ground sampling distance & $7 \mathrm{~cm}$ \\
Speed & $16 \mathrm{~m} / \mathrm{s}$ \\
Flight duration & $14 \mathrm{~min} 36 \mathrm{~s}$ \\
Composite images & 321 \\
Image overlap & $80 \%$ \\
\hline
\end{tabular}


A total of 3576 images were stitched together and radiometrically corrected (Pix4Dfields 1.8.0, Pix4d Inc., San Francisco, CA, USA). Radiometric correction was conducted in Pix4Dfields using all the captured images, including the before-and-after flight CRP images. The radiometric calibration target (the CRP) is a white balance card that provides the reflectance properties of the card across the spectrum of light captured by the camera. This enables the software to calibrate and correct the reflectance of the images accordingly in line with the prevalent atmospheric conditions during the image acquisition. The CRP also assists in reducing sun-angle effects, sensor-angle effects, and shadows. Furthermore, the CRP also has an absolute reference, which gets the absolute reflectance values, making it possible to compare data from several flights. Once processed, a final orthomosaic and a digital elevation model (DEM) GeoTIFF image were generated. The orthomosaic was georeferenced in ArcGIS 10.5 using ground-reference points from Google Earth Pro to an RMSE of less than a pixel $(<3 \mathrm{~cm})$. Images were referenced to the Universal Transverse Mercator (UTM zone 36S) projection.

The maize reflectance data was extracted from the multispectral Altum image. This was done by overlaying the ground-truthed maize chlorophyll measurements and their GPS coordinates in the form of a point map with the UAV multispectral image. The reflectance values were extracted for each coordinate and each UAV spectral band. The image was then used to compute vegetation indices (VIs) detailed in Table 4. VIs selected included various combinations of the multispectral bands specific to vegetation health and chlorophyll, such as the NDVI, the canopy chlorophyll content index (CCCI), and the red-edge chlorophyll index $\left(\mathrm{CI}_{\text {rededge }}\right)$. These vegetation indices were chosen based on their performance in literature [49,71-73].

Table 4. UAV-derived vegetation indices.

\begin{tabular}{|c|c|c|c|}
\hline Vegetation Index & Abbreviation & Equation & Reference \\
\hline $\begin{array}{c}\text { Normalized difference } \\
\text { vegetation index }\end{array}$ & NDVI & $(\mathrm{NIR}-\mathrm{RED}) /(\mathrm{NIR}+\mathrm{RED})$ & Xue and Su [49] \\
\hline $\begin{array}{c}\text { Green normalized difference } \\
\text { vegetation index }\end{array}$ & GNDVI & $\frac{\text { NIR-GREEN }}{\text { NIR+GREEN }}$ & $\begin{array}{c}\text { Naito, Ogawa, Valencia, Mohri, } \\
\text { Urano, Hosoi, Shimizu, Chavez, } \\
\text { Ishitani and Selvaraj [72] }\end{array}$ \\
\hline Red-green ratio index & RGR & $\frac{\text { RED }}{\text { GREEN }}$ & Qiu, et al. [74] \\
\hline $\begin{array}{l}\text { Normalized difference } \\
\text { red-edge index }\end{array}$ & NDRE & $\frac{\text { NIR-RED EDGE }}{\text { NIR+RED EDGE }}$ & Fitzgerald, et al. [75] \\
\hline $\begin{array}{c}\text { Corrected transformed } \\
\text { vegetation index }\end{array}$ & CTVI & $\begin{array}{c}\frac{\mathrm{NDVI}+0.5}{\mathrm{ABS}(\mathrm{NDVI}+0.5)} * \\
(\sqrt{\mathrm{ABS}(\mathrm{NDVI}+0.5})\end{array}$ & $\begin{array}{c}\text { Naito, Ogawa, Valencia, Mohri, } \\
\text { Urano, Hosoi, Shimizu, Chavez, } \\
\text { Ishitani and Selvaraj [72] }\end{array}$ \\
\hline $\begin{array}{l}\text { Infrared percentage } \\
\text { vegetation index }\end{array}$ & IPVI & $\frac{\mathrm{NIR}}{(\mathrm{NIR}+\mathrm{RED})}$ & $\begin{array}{c}\text { Haghighian, Yousefi and } \\
\text { Keesstra [73] }\end{array}$ \\
\hline Soil adjusted vegetation index & SAVI & $\begin{array}{l}\left(\frac{\mathrm{NIR}-\mathrm{RED}}{\mathrm{NIR}+\mathrm{RED}+\mathrm{L}}\right) *(1+\mathrm{L}) \\
\mathrm{L} \text { is a constant between } 0 \text { and } 1 .\end{array}$ & Xue and $\mathrm{Su}[49]$ \\
\hline $\begin{array}{l}\text { Optimized soil adjusted } \\
\text { vegetation index }\end{array}$ & OSAVI & $\frac{\text { NIR-RED }}{\text { NIR+RED }+0.16}$ & Xue and $\mathrm{Su}[49]$ \\
\hline Green chlorophyll index & $\mathrm{CI}_{\text {green }}$ & $(\mathrm{NIR} / \mathrm{GREEN})-1$ & Zhang and Zhou [71] \\
\hline Red-edge chlorophyll index & $\mathrm{CI}_{\text {rededge }}$ & $(\mathrm{NIR}-\mathrm{RED}$ EDGE $)-1$ & Zhang and Zhou [71] \\
\hline $\begin{array}{l}\text { Canopy chlorophyll } \\
\text { content index }\end{array}$ & CCCI & $\frac{\mathrm{NDRE}-\mathrm{NDRE}_{\min }}{\mathrm{NDRE}_{\max }-\mathrm{NDRE}_{\min }}$ & $\begin{array}{l}\text { Fitzgerald, Rodriguez and } \\
\text { O'Leary [75] }\end{array}$ \\
\hline Chlorophyll vegetation index & CVI & $\mathrm{NIR} *\left(\frac{\mathrm{RED}}{\mathrm{GREEN}^{2}}\right)$ & Vincini and Frazzi [55] \\
\hline $\begin{array}{l}\text { Modified chlorophyll } \\
\text { absorption ratio index }\end{array}$ & MCARI & $\frac{1.5[2.5(\mathrm{NIR}-\mathrm{RED})-1.3(\mathrm{NIR}-\mathrm{GREEN})]}{\sqrt{ }\left[(2 \mathrm{NIR}+1)^{2}-(6 \mathrm{NIR}-5 \sqrt{ }(\mathrm{RED}))-0.5\right.}$ & Wu, et al. [76] \\
\hline
\end{tabular}




\subsection{Statistical Analysis}

The random forest algorithm was used to predict maize chlorophyll content since it is renowned for its simplicity, robust nature, and ability to perform well regardless of sample size $[77,78]$. The random forest ensemble is a machine learning algorithm that uses bootstrap aggregation to construct multiple trees on a subset of samples derived from the training data [57]. Decision trees are grown to their maximum capacity with a randomized subset of predictors (UAV-derived spectral data), and each node is split using random subsets of input variables [79]. Furthermore, the random forest regression can identify predictor variables that are influential in the prediction model based on the sum of the reduction in Gini impurity across the nodes of the feature [80].

Specifically, the RGtk2 and rattle packages in RStudio software version 1.4.1564 were used to develop the random forest regression model through numerical inputs. Variables used for the random forest model were the multispectral wavebands (blue, green, red, rededge and NIR) and VIs (Table 4). The outputs of the random forest model were optimized using the variable importance as they determine the most influential bands and VIs in prediction. Variables of low importance were removed throughout the analysis, and the random forest model was continuously modified for optimal prediction. The process of variable selection reduces issues of variable redundancy and multicollinearity, which affect the performance of the regression model.

Before running the random forest algorithm, the data $(n=63)$ were split into $(70 \%)$ training and $(30 \%)$ testing datasets. Specifically, the training data $(n=40)$ were used to train the model while the testing data $(30 \%)(n=19)$ were used to validate the derived models. In tuning, the mtry, which is the number of variables randomly sampled as candidates at each split, and the ntree, which is the number of trees to grow, were used in this study in training each model. All the models were user-defined and fine-tuned to an optimal 500 trees and eight variables. These hyperparameters were attained for numerous iterations. Although a similar number of ntree and mtry were used for all the models, model calibration and validation were stage-specific.

\subsection{Accuracy Assessment of Chlorophyll Content Models}

Accuracy assessments were conducted to evaluate the performance of the regression models of the predicted chlorophyll content. The accuracy metrics used were the coefficient of determination $\left(\mathrm{R}^{2}\right)$, root-mean-squared error (RMSE), and the relative root-mean-squared error (RRMSE). The $R^{2}$ measured the variation between the measured and predicted: foliar temperature and stomatal conductance. The RMSE assessed the error magnitude between the field measurements and modeled foliar temperature and stomatal conductance outputs, while the RRMSE evaluated the accuracy of the model and was used to compare the performance of regression models across maize phenotyping. The RRMSE is calculated by normalizing the mean of each variable RMSE value and expressed as a percentage, where lower percentages are considered more accurate [81].

\section{Results}

\subsection{Descriptive Analysis of UAV-Derived Data and Ground-Based Maize Data}

Chlorophyll content varied over the maize growth cycle. Table 5 illustrates the descriptive statistics of maize leaf chlorophyll content. The lowest chlorophyll concentration was attained during the early vegetative growth stage (V5-V10) at $172.9 \mu \mathrm{mol} / \mathrm{m}^{-2}$ (Table 5). The highest chlorophyll concentration was recorded during the early reproductive stage (R1-R3) at $1087.3 \mu \mathrm{mol} / \mathrm{m}^{-2}$. The average and median of maize chlorophyll, across the growth stages were $519.5 \mu \mathrm{mol} / \mathrm{m}^{-2}$ and $508 \mu \mathrm{mol} / \mathrm{m}^{-2}$, respectively. The average standard deviation of chlorophyll values were 725.4, which indicated a large deviation of the measurements from the mean value of 519.5. 
Table 5. Descriptive statistics of maize chlorophyll content throughout the various growth stages.

\begin{tabular}{|c|c|c|c|c|c|c|}
\hline $\begin{array}{l}\text { Day of Year } \\
\text { (DOY) }\end{array}$ & $\begin{array}{l}\text { Chlorophyll Content at } \\
\text { Various Growth Stages }\end{array}$ & $\begin{array}{l}\text { Minimum } \\
\left(\mu \mathrm{mol} / \mathrm{m}^{-2}\right)\end{array}$ & $\begin{array}{l}\text { Maximum } \\
\left(\mu \mathrm{mol} / \mathrm{m}^{-2}\right)\end{array}$ & $\begin{array}{c}\text { Mean } \\
\left(\mu \mathrm{mol} / \mathrm{m}^{-2}\right)\end{array}$ & $\begin{array}{c}\text { Median } \\
\left(\mu \mathrm{mol} / \mathrm{m}^{-2}\right)\end{array}$ & $\begin{array}{l}\text { Standard } \\
\text { Deviation }\end{array}$ \\
\hline 61 & V5-V10 & 172.9 & 542.1 & 336.3 & 334.1 & 89.8 \\
\hline 77 & V12 & 337.2 & 1051.1 & 600.4 & 585.8 & 128.1 \\
\hline 90 & V14-VT & 438.5 & 1015.7 & 643.3 & 613.7 & 126.7 \\
\hline 102 & R1-R2 & 406.6 & 1087.3 & 660.2 & 649.2 & 137.6 \\
\hline 118 & R2-R4 & 240.3 & 883.7 & 535.8 & 528.0 & 142.3 \\
\hline 134 & R4-R5 & 191.5 & 706.8 & 340.9 & 337.2 & 100.9 \\
\hline \multicolumn{2}{|c|}{ Average value } & 297.8 & 881.1 & 519.5 & 508 & 725.4 \\
\hline
\end{tabular}

\subsection{Random Forest Models of Maize Chlorophyll Content}

3.2.1. Optimized Regression Models of Maize Chlorophyll Content over the Various Growth Stages

The relationship of measured (SPAD derived) and modeled (UAV derived) chlorophyll content varied across the various maize growth stages. The model optimally estimated the chlorophyll content throughout the various growth stages; however, the prediction of chlorophyll proved more accurate during the vegetative growth stages. During the early vegetative growth stage (V5-V10), the RMSE accuracy achieved was $61.6 \mu \mathrm{mol} / \mathrm{m}^{-2}$, with an $R^{2}=0.80$ and RRMSE $=8 \%$ (Figure 5a). The mid-vegetative growth stage (V12) obtained an RMSE $=61.9 \mu \mathrm{mol} / \mathrm{m}^{-2}, \mathrm{R}^{2}=0.79$ and RRMSE $=10 \%$ (Figure $5 \mathrm{~b}$ ), whereas the late vegetative growth stage (V14-VT) produced the lowest RMSE $=39 \mu \mathrm{mol} / \mathrm{m}^{-2}, \mathrm{R}^{2}=0.87$ and an RRMSE model accuracy of $7 \%$ (Figure $5 \mathrm{c}$ ).
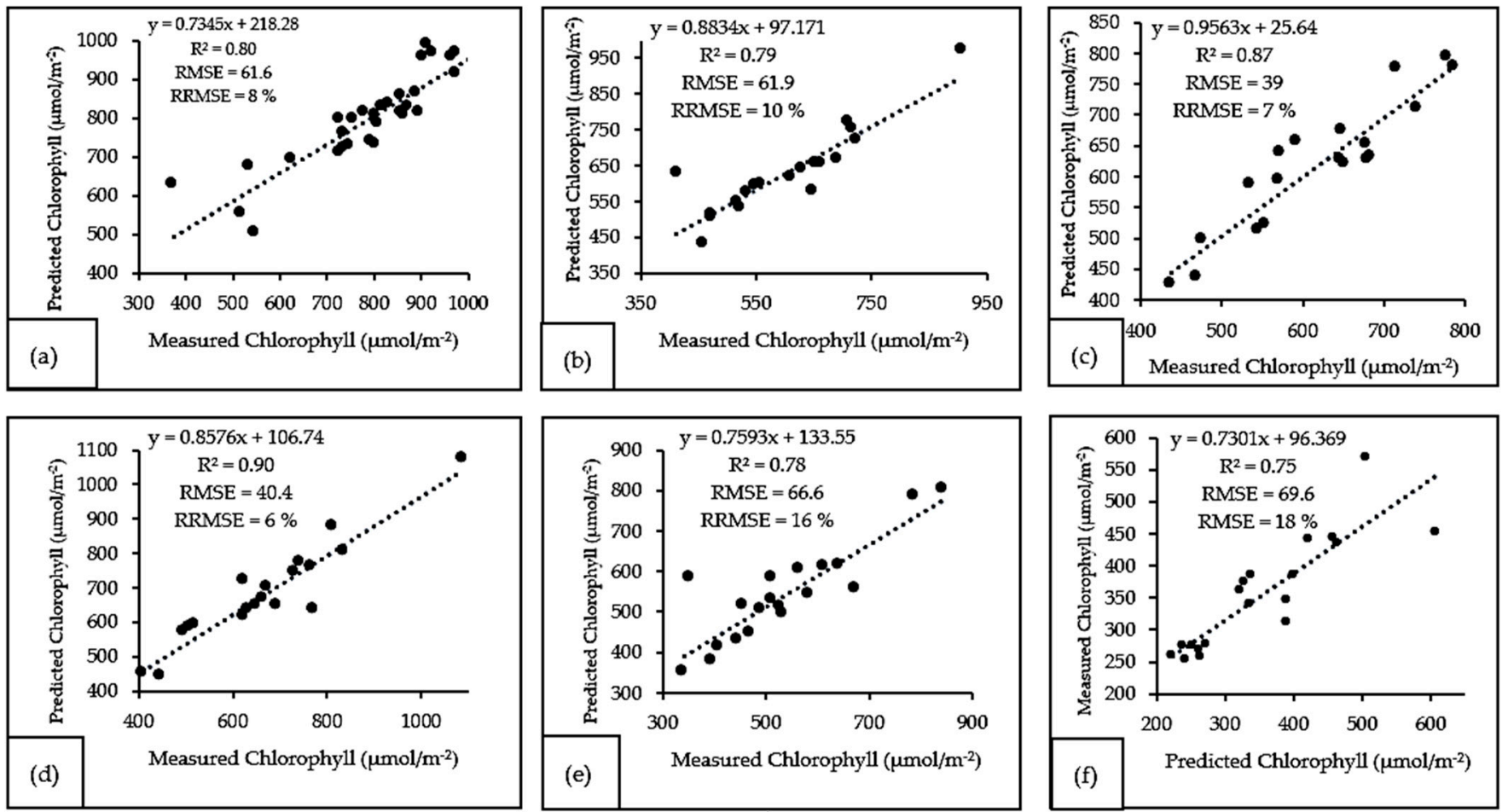

Figure 5. Linear relationships between measured and predicted maize chlorophyll content for vegetative stages (a) V5-V10, (b) V12, (c) V14 to VT, and reproductive stages (d) R1-R3, (e) R3-R4, (f) R5-R6. The model calibration and validation were stage-specific.

Similarly, the early reproductive development stage (R1-R2) obtained a low RMSE $=40.4 \mu \mathrm{mol} / \mathrm{m}^{-2}, \mathrm{R}^{2}=0.90$ but produced the highest RRMSE accuracy of $6 \%$ (Figure 5d). The RMSE accuracies during the mid-reproductive (R2-R4) and late reproductive (R4-R5) growth stages were $66.6 \mu \mathrm{mol} / \mathrm{m}^{-2}$ and $69.6 \mu \mathrm{mol} / \mathrm{m}^{-2}$, respectively. 
However, the model produced the lowest RRMSE and $\mathrm{R}^{2}$ accuracies during the R2-R4 and R4-R5 stages at an RRMSE of $16 \%, R^{2}=0.78$ (Figure $5 e$ ) and an RRMSE of $18 \%$, $R^{2}=0.75$ (Figure $5 f$ ), respectively.

\subsubsection{Variable Importance of Maize Chlorophyll Content Models over the Various} Growth Stages

The early reproductive (R1-R3) growth stage produced the most optimal model performance in general, with an RRMSE $=6 \%$ and $R^{2}=0.90$. The top VIs and spectral bands selected by the model for the early reproductive growth stage were the NDRE, NIR, CIrededge, NDVI, and the red-edge, amongst others, in order of importance (Figure 6d). The late vegetative (V14-VT) growth stage also yielded a high model RRMSE $=7 \%$ and $\mathrm{R}^{2}=0.87$ based on the CCCI, NDVI, NIR, red-edge, amongst others (Figure 6c). The aforementioned variables of importance for the R1-R3 and V14-VT stages were major contributors in modeling chlorophyll content, as there was a major step down in the importance of the other VIs and bands. Similarly, the mid-vegetative (V12) and midreproductive (R4-R5) have major standout importance variables of MCARI, CCCI, red-edge and then the NIR, red-edge, MCARI, amongst others, respectively. On the other hand, the early vegetative (V5-V10) and late reproductive (R5-R6) stages gradually decrease variable importance scores based on the NDRE, $\mathrm{CI}_{\text {rededge, }}$ NDVI, NIR and NIR, red-edge, MCARI and OSAVI, amongst others, respectively. In general, the variables obtaining the highest importance scores were derived from the NIR, red-edge and red wavebands.
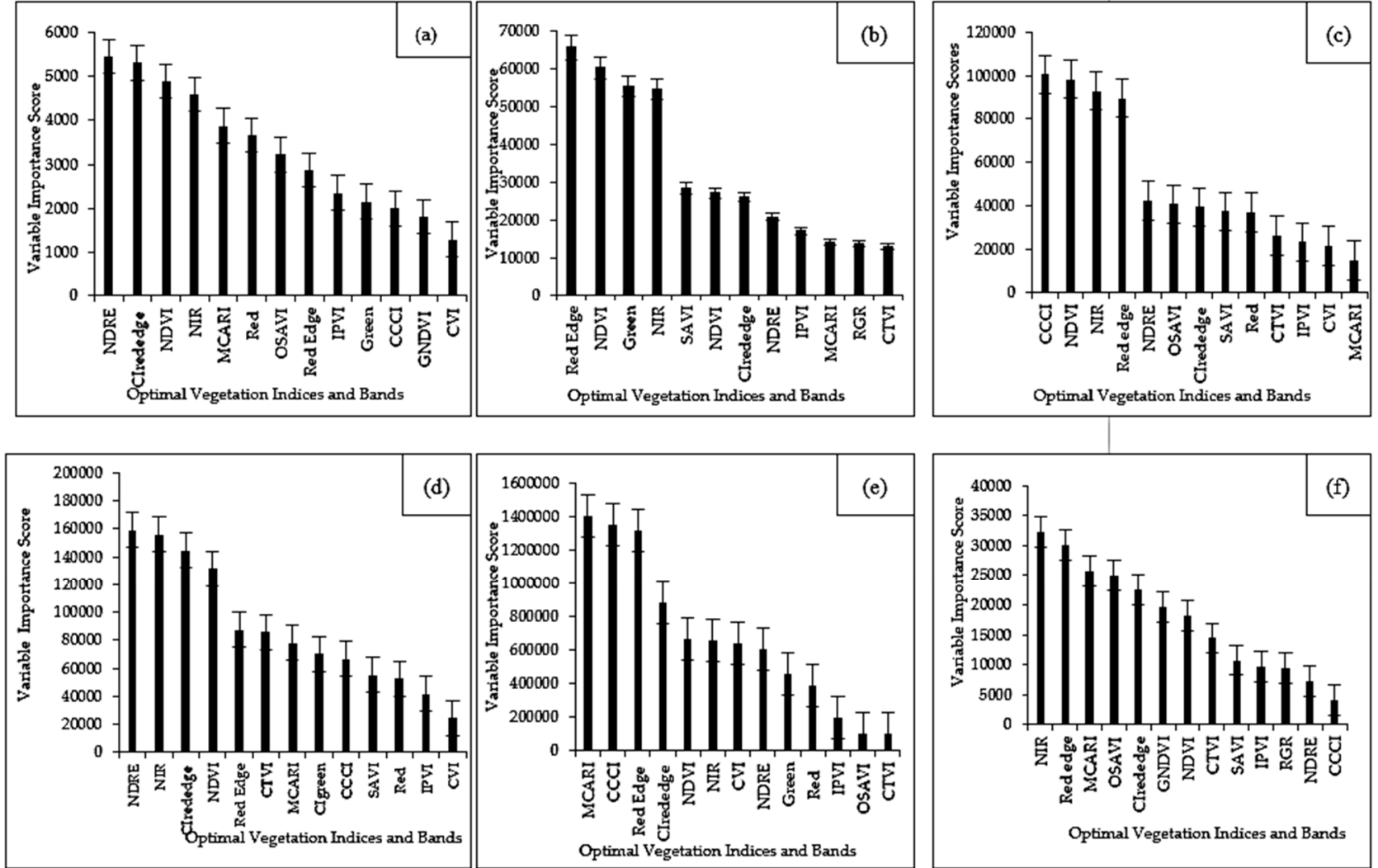

Figure 6. Variable importance scores of optimal chlorophyll content VIs and bands for vegetative stages (a) V5-V10, (b) V12, (c) V14 to VT, and reproductive stages (d) R1-R3, (e) R3-R4, (f) R5-R6. The model calibration and validation were stage-specific.

3.2.3. Mapping the Spatial Distribution of Maize Chlorophyll Content over the Various Growth Stages

The modeled chlorophyll concentrations ranged from $198 \mu \mathrm{mol} / \mathrm{m}^{-2}$ to $340 \mu \mathrm{mol} / \mathrm{m}^{-2}$ (Figure 7). The chlorophyll content index of maize was low during the early vegetative 
growth stage (V5-V10) and then progressively increased throughout the various growth stages. In the late vegetative (V14-VT), early reproductive (R1-R3), and mid-reproductive (R4-R5) growth stages, the chlorophyll concentrations were the highest. Subsequently, chlorophyll content was depleted during the late reproductive stage (R5-R6).
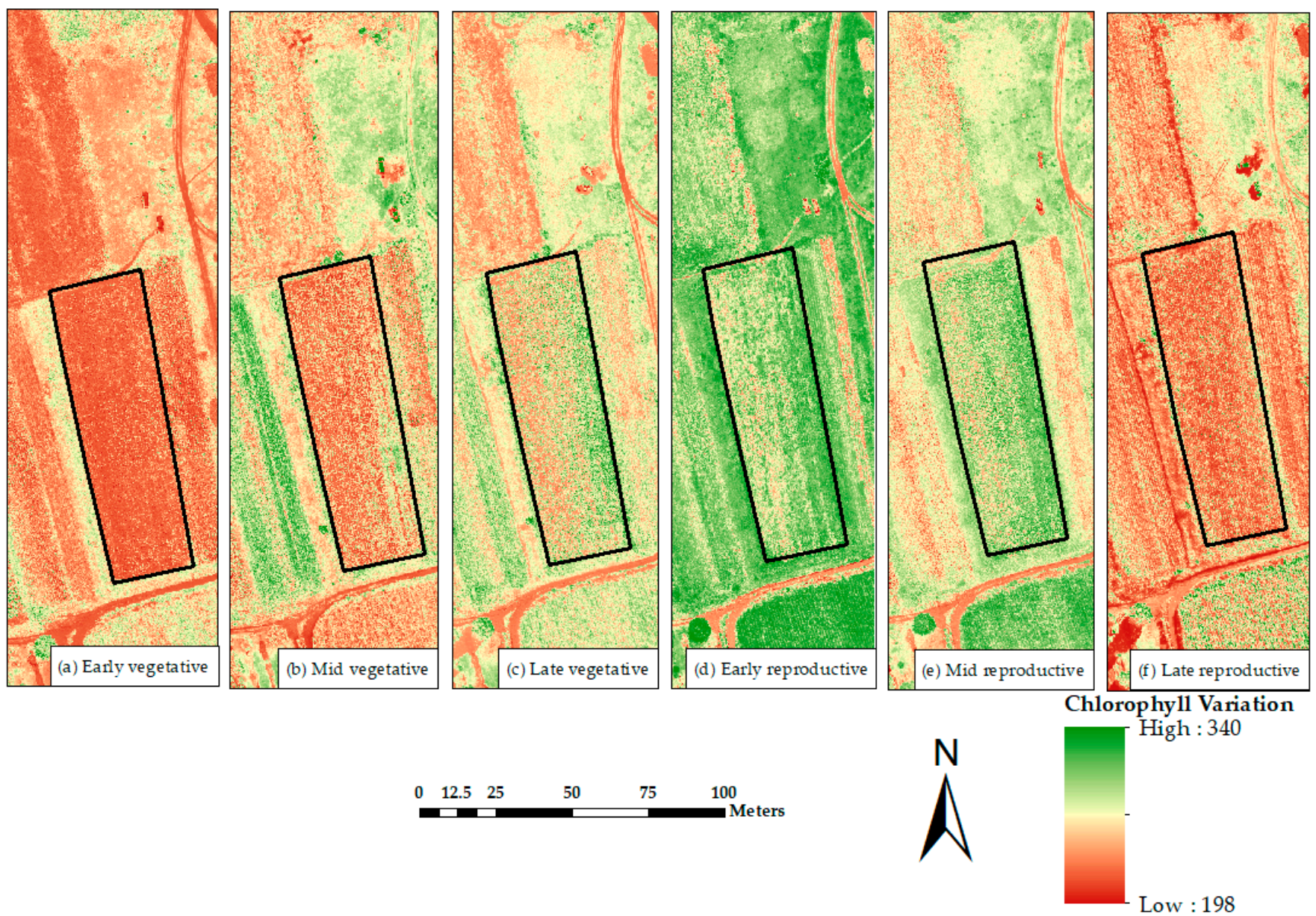

Figure 7. Spatial distribution of chlorophyll content over the maize field for vegetative stages (a) V5-V10, (b) V12, (c) V14 to VT, and reproductive stages (d) R1-R3, (e) R3-R4, (f) R5-R6.

\section{Discussion}

This study aimed to predict chlorophyll content variations across maize phenological stages using UAV-derived VIs and the random forest algorithm. In doing so, we attempted to determine the optimal maize growth stage(s) for chlorophyll prediction. It is evident that chlorophyll concentrations varied over the phenological stages, and the model could discern the optimal growth stage for estimating chlorophyll. The chlorophyll variations of maize over the growing season are useful for estimating the health and productivity status of the smallholder field.

\subsection{Estimating Maize Chlorophyll Content across the Growing Season}

The findings of the study's model performed well throughout the vegetative growth stages. The earliest vegetative growth stage yielded an RMSE accuracy of $61.6 \mu \mathrm{mol} / \mathrm{m}^{-2}$, $R^{2}=0.80$ (RRMSE $=8 \%$ ) based on the NDRE, CIrededge, NDVI, and NIR as the most influential variables (in order of importance). Specifically, the red-edge and NIR regions were identified as crucial wavelengths in the model's prediction of chlorophyll content due to their association with healthier plants. This is because the red-edge wavelength is sensitive to plants with high chlorophyll content, nitrogen content, and biomass, and thus are better predicted using the red-edge $[31,32,82]$. Additionally, the NIR region strongly 
influences the prediction of chlorophyll content, as it is sensitive to the high foliar reflectance induced by the pigment concentrations of plant canopy structures $[83,84]$. The studies of Sibanda, Mutanga, Dube and Mafongoya [31] and Singhal et al. [85] demonstrated a similar association between the red-edge and NIR regions with chlorophyll content by achieving an $R^{2}$ of 0.91 and 0.90 , respectively. Strong chlorophyll concentrations were associated with crop emergence and development in this study. The leaf-area index was low, resulting in more dynamic photosynthetic rates of the crop, which facilitated high reflectance in the rededge and NIR regions. Furthermore, red-edge and NIR-derived VIs are known to surpass the effects of atmospheric interferences, visible irradiance, variable background effects, and geometrical arrangement of a scene when compared to conventional bands [86,87]. Thus, the red-edge and NIR wavelengths facilitated optimal maize chlorophyll prediction. The low foliage density of the early vegetative growth stage did not saturate and caused spectral confusion of the sensor during image acquisition. Furthermore, the relationship between chlorophyll concentration, red-edge, NIR, and their derived vegetation indices have been noted to be critical in crop health assessment $[85,88,89]$.

During the mid-vegetative growth stage, the major variables of importance were derived from the NIR region; however, the green waveband was also identified as a significant contributor towards model estimation. This may be attributed to the high biomass accumulation, increase in leaf-foliage density associated with high chlorophyll concentrations. Chlorophyll rapidly increased at this stage from a mean of $336.3 \mu \mathrm{mol} / \mathrm{m}^{-2}$ during early vegetative stage to $600.4 \mu \mathrm{mol} / \mathrm{m}^{-2}$ during mid-vegetative growth. Moreover, literature has stated that a moderate-to-high increase in chlorophyll concentrations during maize growth results in less sensitivity of the red band and more sensitivity in the green band $[90,91]$. This further explains why the green band was identified as a variable of significantly high importance only during mid-vegetative growth. Thus, such findings from the prediction model and the continuous increase in SRS-NDVI values suggested the optimal growth and productivity of the smallholder maize field.

Meanwhile, high chlorophyll concentrations have been associated with the late vegetative and early reproductive growth stages, as maize reaches photosynthetic maturity and requires high productivity to begin fruit production [92]. Results from this study showed a similar trend, as the model prediction accuracies were most optimal during the late vegetative and early reproductive with an RRMSE accuracy of $7 \%$ and $6 \%$ and $\mathrm{R}^{2}$ values of 0.87 and 0.90 , respectively. Such results are attributed to the fact that the reflectance of maize-leaf chlorophyll content during the late vegetative and early reproductive stages are stronger than other stages of phenotyping due to the high leaf area index and full canopy closure characterized by these stages [9,93]. It has been documented in studies by Walker, Drewry, Slattery, VanLoocke, Cho and Ort [93], Dahms et al. [94] and Costa et al. [95] that during the stages of tasseling silking and pollination, maize is characterized by a fully developed leaf canopy structure with a high leaf area index that promotes the detection of higher chlorophyll content. Hence, the dense canopy architecture and absence of soil background effect created a homogenous scene of green pigment reflectance, which was optimal in predicting chlorophyll content over the smallholder field.

Similarly to the early vegetative stages, the NIR and red-edge bands were significant variables of maize chlorophyll prediction due to these regions' favorable detection of high chlorophyll reflectance. The biochemical properties of a dense foliar canopy are the thick waxy cuticle, air cavities, chloroplasts, and mesophyll cell thickness all contribute to the high NIR ad red-edge reflectance, directly correlated with chlorophyll content $[80,96]$. Such findings of the chlorophyll estimation during the late vegetative and early reproductive, supported by the high measured SPAD chlorophyll values of these stages, are associated with a healthier crop and further coincide with the SRS-NDVI values of approximately 0.65. In this regard, the high levels of chlorophyll content were favorable in model prediction, hence these stages being the most accurate in estimation.

The model prediction accuracies were lowest during the mid-reproductive and latereproductive stages, with an RRMSE of $16 \%$ and $18 \%$ and $R^{2}$ values of 0.78 and 0.75 , 
respectively. The low model-prediction accuracies could be attributed to the adverse effects of a hailstorm that damaged the maize canopy structure, resulting in a lower crop chlorophyll content. The physical damage to the maize canopy exposed the underlying soil surface that consisted of damaged and decayed maize leaves. This resulted in spectral confusion due to the hybrid of soil and senescing leaf reflectance imaged by the MicaSense Altum camera, resulting in the failure of the model to discern the apparent chlorophyll variations. This is due to the predominant brown tone of the senescing leaves and soil that resulted in most bands and VIs being absorbed due to the low chlorophyll concentrations, whereas wavelengths such as the red band reflected much higher. Nevertheless, an apparent decline in NDVI values prior to the hailstorm was evident and was associated with a decline in chlorophyll. This may be because, at this point in phenotyping, the crop channels its nutritional resources and energy towards fruit production [93], resulting in a reduction of chlorophyll concentration that is also apparent in the results.

\subsection{Implications of the Study}

Smallholder farmers constantly strive to maximize their small-scale crop production and produce healthy and productive yields. However, they are seldom the focus of innovation and lack resources, as it is always assumed that their scale of operations does not necessitate such. Thus, such findings demonstrate the use of precision agricultural technologies (i.e., UAVs), which can facilitate improved smallholder agricultural management. Specifically, UAV-derived data are near-real-time, enabling quick and effective management that may improve crop health and productivity. Moreover, near-real-time data are particularly useful when there are erratic weather conditions, such as the hailstorm occurrence. Such agrometeorological effects prove how smallholder farmers are subjected to the variability of weather and climate, which has consequences on crop growth, health, and the overall productivity of their farms. In such instances, UAV-derived data could be used to rapidly assess likely hail damage in near-real-time, allowing farmers to make informed and effective decisions on agricultural management to provide warning for food insecurity. Therefore, near-real-time UAV technology is beneficial in smallholder agricultural systems as it allows for rapid and informed decisions to limit further crop-health issues.

\section{Limitations and Recommendations}

Although the UAV onboard sensor availed a high spatial resolution, the spectral resolution of the sensor limited the multispectral bands and derived vegetation indices choices. The use of higher-spectral resolution data may allow for more precise spectral extraction, especially during the early growth stages when the crop foliar canopy has not developed. Moreover, high precision and accuracy of GPS gadgets with up to a cm accuracy need to be considered during the sampling procedure. There is a need for future studies to consider other applications such as masking, different algorithms, and maize varieties in generating crop-health assessment models. Furthermore, this may also result in improved model performance and more detailed map outputs of chlorophyll content across the study area. The use of a higher hyperspectral sensor may assist with this limitation of the study; however, these sensors have a high acquisition cost that is not feasible towards near-real-time smallholder applications.

Moreover, this study used two sets of data to train and test the model. However, some studies achieved improved results due to incorporating a third set of independent data to test the model. Therefore, it is recommended that further analysis of model performance is undertaken in future, when and if more data become available. Nevertheless, the synergistic application of UAV-derived data with a predictive random forest algorithm proved to be instrumental in assisting smallholder farmers in near-real-time to make the necessary management decisions. 


\section{Conclusions}

Smallholder farming systems lack the required resources to maximize their productivity and monitor croplands for healthy growth and development. In recent years, the synergistic use of UAV remotely sensed technology and crop-health proxies such as chlorophyll content have facilitated a deeper understanding of crop dynamics. In this regard, the study tested the utility of UAV-derived multispectral data by estimating maize chlorophyll content over the various stages of phenotyping. This was done using a random forest prediction model, which estimated the chlorophyll concentrations of maize in smallholder farms of Swayimani. Therefore, premised on the findings of the study, it is concluded that:

- Optimal chlorophyll-content prediction accuracies were produced during early vegetative growth stages (V5-V10 and V12), late vegetative growth stages (V14-VT), and early reproductive growth stages (R1-R3),

- Maize chlorophyll content was optimally estimated through UAV-derived NIR and red-edge wavelengths.

Since chlorophyll content has been widely illustrated as a proxy of crop health, the study's findings imply that UAV-derived data could be optimally utilized to characterize the general state of maize health in smallholder cropping lands, with significantly improved spatial accuracies. The findings displayed optimal maize crop health and productivity across phenotyping; however, the occurrence of a hailstorm damaged the canopy structure and had adverse consequences on the smallholder maize health status. Such precision technology advancements are a low-cost, objective, and accurate technique that smallholder farmers can adapt to inform decision-making and agricultural management. Specifically, multispectral UAV technology is spatially explicit and provides near-real-time data for understanding crop health through the biochemical indicator of chlorophyll. This technology potentially overcomes some limitations associated with satellite imagery. However, the study could have benefited from higherspectral resolution data and the third independent testing data set to improve the model performance. Nevertheless, the random forest model successfully predicted the chlorophyll content in smallholder farms. Therefore, multispectral UAV technology is a beneficial solution to smallholder agriculture. It provides farmers with information on crop dynamics at user-defined spatial and temporal scales for improved management and overall productivity.

Author Contributions: Conceptualization, K.B., A.C., M.S. and T.M.; methodology, K.B., A.C., M.S., S.G., V.N. and T.M.; software, K.B., V.N., A.C., M.S. and T.M.; validation, K.B., M.S. and A.C.; formal analysis, K.B., M.S. and A.C.; investigation, K.B., M.S., A.C., S.G. and T.M.; resources, K.B., A.C., V.N. and T.M.; data curation, K.B.; writing-original draft preparation, K.B.; writing-review and editing, K.B., M.S., A.C. and S.G.; supervision, A.C. and M.S.; project administration, M.S. and T.M.; funding acquisition, T.M. All authors have read and agreed to the published version of the manuscript.

Funding: This research was funded by the Water Research Commission of South Africa (WRC) through the Project WRC K5/2971//4 titled the "Use of drones in monitoring crop health, water stress, crop water requirements, and improvements on crop water productivity to enhance precision agriculture and irrigation scheduling", and in part by the National Research Foundation of South Africa (Grant Number: 122140).

Data Availability Statement: The data presented in this study are available on request from the corresponding author. The data are not publicly available due to authorization restrictions from the funder that limit the distribution of data, as the article is part of an ongoing project where other manuscripts are still being prepared.

Acknowledgments: The authors would like to acknowledge the Swayimani smallholder farmers and Swayimani High School. The authors would like to thank Onisimo Mutunga, John Odindi, Trylee Matongera Vimbayi Chimonyo, Serge Kiala, Siphiwokuhle Buthelezi, Amanda Nyawose, and Helen Ndlovu.

Conflicts of Interest: The authors declare no conflict of interest. 


\section{References}

1. Kamara, A.; Conteh, A.; Rhodes, E.R.; Cooke, R.A. The relevance of smallholder farming to African agricultural growth and development. Afr. J. Food Agric. Nutr. Dev. 2019, 19, 14043-14065. [CrossRef]

2. Salami, A.; Kamara, A.B.; Brixiova, Z. Smallholder Agriculture in East Africa: Trends, Constraints and Opportunities; African Development Bank Tunis: Tunis, Tunisia, 2010.

3. Adisa, O.M.; Botai, C.M.; Botai, J.O.; Hassen, A.; Darkey, D.; Tesfamariam, E.; Adisa, A.F.; Adeola, A.M.; Ncongwane, K.P. Analysis of agro-climatic parameters and their influence on maize production in South Africa. Theor. Appl. Climatol. 2018, 134, 991-1004. [CrossRef]

4. Vanlauwe, B.; Coyne, D.; Gockowski, J.; Hauser, S.; Huising, J.; Masso, C.; Nziguheba, G.; Schut, M.; Van Asten, P. Sustainable intensification and the African smallholder farmer. Curr. Opin. Environ. Sustain. 2014, 8, 15-22. [CrossRef]

5. Tefera, T.; Kanampiu, F.; De Groote, H.; Hellin, J.; Mugo, S.; Kimenju, S.; Beyene, Y.; Boddupalli, P.M.; Shiferaw, B.; Banziger, M. The metal silo: An effective grain storage technology for reducing post-harvest insect and pathogen losses in maize while improving smallholder farmers' food security in developing countries. Crop Prot. 2011, 30, 240-245. [CrossRef]

6. Unganai, L.S.; Murwira, A. Challenges and opportunities for climate change adaptation among smallholder farmers in southeast Zimbabwe. In Proceedings of the 2nd International Conference: Climate, Sustainability and Development in Semi-Arid Regions, Fortaleza, Brazil, 16-20 August 2010; pp. 16-20.

7. Okonya, J.S.; Syndikus, K.; Kroschel, J. Farmers' perception of and coping strategies to climate change: Evidence from six agro-ecological zones of Uganda. J. Agric. Sci. 2013, 5, 252. [CrossRef]

8. Muzari, W.; Gatsi, W.; Muvhunzi, S. The impacts of technology adoption on smallholder agricultural productivity in sub-Saharan Africa: A review. J. Sustain. Dev. 2012, 5, 69. [CrossRef]

9. Walker, N.; Schulze, R. An assessment of sustainable maize production under different management and climate scenarios for smallholder agro-ecosystems in KwaZulu-Natal, South Africa. Phys. Chem. Earth Parts A/B/C 2006, 31, 995-1002. [CrossRef]

10. Nhamo, L.; Magidi, J.; Nyamugama, A.; Clulow, A.D.; Sibanda, M.; Chimonyo, V.G.; Mabhaudhi, T. Prospects of Improving Agricultural and Water Productivity through Unmanned Aerial Vehicles. Agriculture 2020, 10, 256. [CrossRef]

11. Shi, Y.; Thomasson, J.A.; Murray, S.C.; Pugh, N.A.; Rooney, W.L.; Shafian, S.; Rajan, N.; Rouze, G.; Morgan, C.L.; Neely, H.L. Unmanned aerial vehicles for high-throughput phenotyping and agronomic research. PLoS ONE 2016, 11, e0159781. [CrossRef] [PubMed]

12. Nicholls, C.I.; Altieri, M.A.; Dezanet, A.; Lana, M.; Feistauer, D.; Ouriques, M. A rapid, farmer-friendly agroecological method to estimate soil quality and crop health in vineyard systems. Biodynamics 2004, 33-39.

13. Hernández-Clemente, R.; Hornero, A.; Mottus, M.; Peñuelas, J.; González-Dugo, V.; Jiménez, J.; Suárez, L.; Alonso, L.; ZarcoTejada, P.J. Early diagnosis of vegetation health from high-resolution hyperspectral and thermal imagery: Lessons learned from empirical relationships and radiative transfer modelling. Curr. For. Rep. 2019, 5, 169-183. [CrossRef]

14. Whitford, W.G.; De Soyza, A.G.; Van Zee, J.W.; Herrick, J.E.; Havstad, K.M. Vegetation, soil, and animal indicators of rangeland health. Environ. Monit. Assess. 1998, 51, 179-200. [CrossRef]

15. Sahu, P.K.; Singh, D.P.; Prabha, R.; Meena, K.K.; Abhilash, P. Connecting microbial capabilities with the soil and plant health: Options for agricultural sustainability. Ecol. Indic. 2019, 105, 601-612. [CrossRef]

16. Krupa, S.; McGrath, M.T.; Andersen, C.P.; Booker, F.L.; Burkey, K.O.; Chappelka, A.H.; Chevone, B.I.; Pell, E.J.; Zilinskas, B.A. Ambient ozone and plant health. Plant Dis. 2001, 85, 4-12. [CrossRef] [PubMed]

17. Chahal, I.; Hooker, D.; Deen, B.; Janovicek, K.; Van Eerd, L. Long-term effects of crop rotation, tillage, and fertilizer nitrogen on soil health indicators and crop productivity in a temperate climate. Soil Tillage Res. 2021, 213, 105121. [CrossRef]

18. Guo, S.; Xiong, W.; Hang, X.; Gao, Z.; Jiao, Z.; Liu, H.; Mo, Y.; Zhang, N.; Kowalchuk, G.A.; Li, R. Protists as main indicators and determinants of plant performance. Microbiome 2021, 9, 64. [CrossRef]

19. Flynn, K.C.; Frazier, A.E.; Admas, S. Performance of chlorophyll prediction indices for Eragrostis tef at Sentinel-2 MSI and Landsat-8 OLI spectral resolutions. Precis. Agric. 2020, 21, 1057-1071. [CrossRef]

20. Pavlovic, D.; Nikolic, B.; Djurovic, S.; Waisi, H.; Andjelkovic, A.; Marisavljevic, D. Chlorophyll as a Measure of Plant Health: Agroecological Aspects; Institute of Pesticides and Environmental Protection: Belgrade, Serbia, 2015.

21. Tahir, M.N.; Naqvi, S.Z.A.; Lan, Y.; Zhang, Y.; Wang, Y.; Afzal, M.; Cheema, M.J.M.; Amir, S. Real time estimation of chlorophyll content based on vegetation indices derived from multispectral UAV in the kinnow orchard. Int. J. Precis. Agric. Aviat. 2018, 1, 24-31.

22. Terashima, I.; Fujita, T.; Inoue, T.; Chow, W.S.; Oguchi, R. Green light drives leaf photosynthesis more efficiently than red light in strong white light: Revisiting the enigmatic question of why leaves are green. Plant Cell Physiol. 2009, 50, 684-697. [CrossRef]

23. Mamrutha, H.; Sharma, D.; Kumar, K.S.; Venkatesh, K.; Tiwari, V.; Sharma, I. Influence of diurnal irradiance variation on chlorophyll values in wheat: A comparative study using different chlorophyll meters. Natl. Acad. Sci. Lett. 2017, 40, 221-224. [CrossRef]

24. Boggs, J.L.; Tsegaye, T.; Coleman, T.L.; Reddy, K.; Fahsi, A. Relationship between hyperspectral reflectance, soil nitrate-nitrogen, cotton leaf chlorophyll, and cotton yield: A step toward precision agriculture. J. Sustain. Agric. 2003, 22, 5-16. [CrossRef]

25. Dey, A.K.; Sharma, M.; Meshram, M. An analysis of leaf chlorophyll measurement method using chlorophyll meter and image processing technique. Procedia Comput. Sci. 2016, 85, 286-292. [CrossRef] 
26. Zhang, X.; He, Y.; Wang, C.; Xu, F.; Li, X.; Tan, C.; Chen, D.; Wang, G.; Shi, L. Estimation of Corn Canopy Chlorophyll Content Using Derivative Spectra in the O2-A Absorption Band. Front. Plant Sci. 2019, 10, 1047. [CrossRef] [PubMed]

27. Afzal, A.; Mousavi, S.-F. Estimation of moisture in maize leaf by measuring leaf dielectric constant. Int. J. Agric. Biol. 2008, 10, 66-68.

28. Li, X.; Liu, X.; Liu, M.; Wang, C.; Xia, X. A hyperspectral index sensitive to subtle changes in the canopy chlorophyll content under arsenic stress. Int. J. Appl. Earth Obs. Geoinf. 2015, 36, 41-53. [CrossRef]

29. Wu, B.; Meng, J.; Li, Q.; Yan, N.; Du, X.; Zhang, M. Remote sensing-based global crop monitoring: Experiences with China's CropWatch system. Int. J. Digit. Earth 2014, 7, 113-137. [CrossRef]

30. Pinter, P.J., Jr.; Hatfield, J.L.; Schepers, J.S.; Barnes, E.M.; Moran, M.S.; Daughtry, C.S.; Upchurch, D.R. Remote sensing for crop management. Photogramm. Eng. Remote Sens. 2003, 69, 647-664. [CrossRef]

31. Sibanda, M.; Mutanga, O.; Dube, T.; Mafongoya, P.L. Spectrometric proximally sensed data for estimating chlorophyll content of grasslands treated with complex fertilizer combinations. J. Appl. Remote Sens. 2020, 14, 024517. [CrossRef]

32. Delegido, J.; Verrelst, J.; Alonso, L.; Moreno, J. Evaluation of Sentinel-2 Red-Edge Bands for Empirical Estimation of Green LAI and Chlorophyll Content. Sensors 2011, 11, 7063-7081. [CrossRef]

33. Kooistra, L.; Clevers, J.G. Estimating potato leaf chlorophyll content using ratio vegetation indices. Remote Sens. Lett. 2016, 7 , 611-620. [CrossRef]

34. Kanning, M.; Kühling, I.; Trautz, D.; Jarmer, T. High-resolution UAV-based hyperspectral imagery for LAI and chlorophyll estimations from wheat for yield prediction. Remote Sens. 2018, 10, 2000. [CrossRef]

35. Duveiller, G.; López-Lozano, R.; Baruth, B. Enhanced processing of 1-km spatial resolution fAPAR time series for sugarcane yield forecasting and monitoring. Remote Sens. 2013, 5, 1091-1116. [CrossRef]

36. Miao, Y.; Mulla, D.J.; Randall, G.W.; Vetsch, J.A.; Vintila, R. Combining chlorophyll meter readings and high spatial resolution remote sensing images for in-season site-specific nitrogen management of corn. Precis. Agric. 2009, 10, 45-62. [CrossRef]

37. Nhamo, L.; Van Dijk, R.; Magidi, J.; Wiberg, D.; Tshikolomo, K. Improving the accuracy of remotely sensed irrigated areas using post-classification enhancement through UAV capability. Remote Sens. 2018, 10, 712. [CrossRef]

38. Berra, E.; Peppa, M. Advances and Challenges of UAV SFM MVS Photogrammetry and Remote Sensing: Short Review. In Proceedings of the 2020 IEEE Latin American GRSS \& ISPRS Remote Sensing Conference (LAGIRS), Santiago, Chile, 22-26 March 2020; pp. 533-538.

39. Psirofonia, P.; Samaritakis, V.; Eliopoulos, P.; Potamitis, I. Use of unmanned aerial vehicles for agricultural applications with emphasis on crop protection: Three novel case-studies. Int. J. Agric. Sci. Technol. 2017, 5, 30-39. [CrossRef]

40. Cobo, J.G.; Dercon, G.; Cadisch, G. Nutrient balances in African land use systems across different spatial scales: A review of approaches, challenges and progress. Agric. Ecosyst. Environ. 2010, 136, 1-15. [CrossRef]

41. Zhang, C.; Kovacs, J.M. The application of small unmanned aerial systems for precision agriculture: A review. Precis. Agric. 2012, 13, 693-712. [CrossRef]

42. Khechba, K.; Laamrani, A.; Dhiba, D.; Misbah, K.; Chehbouni, A. Monitoring and Analyzing Yield Gap in Africa through Soil Attribute Best Management Using Remote Sensing Approaches: A Review. Remote Sens. 2021, 13, 4602. [CrossRef]

43. Sadeh, Y.; Zhu, X.; Dunkerley, D.; Walker, J.P.; Zhang, Y.; Rozenstein, O.; Manivasagam, V.; Chenu, K. Fusion of Sentinel-2 and PlanetScope time-series data into daily $3 \mathrm{~m}$ surface reflectance and wheat LAI monitoring. Int. J. Appl. Earth Obs. Geoinf. 2021, 96, 102260. [CrossRef]

44. Maes, W.H.; Steppe, K. Perspectives for remote sensing with unmanned aerial vehicles in precision agriculture. Trends Plant Sci. 2019, 24, 152-164. [CrossRef] [PubMed]

45. Xiang, H.; Tian, L. Development of a low-cost agricultural remote sensing system based on an autonomous unmanned aerial vehicle (UAV). Biosyst. Eng. 2011, 108, 174-190. [CrossRef]

46. Dehkordi, R.H.; Denis, A.; Fouche, J.; Burgeon, V.; Cornelis, J.T.; Tychon, B.; Gomez, E.P.; Meersmans, J. Remotely-sensed assessment of the impact of century-old biochar on chicory crop growth using high-resolution UAV-based imagery. Int. J. Appl. Earth Obs. Geoinf. 2020, 91, 102147.

47. Rasmussen, J.; Ntakos, G.; Nielsen, J.; Svensgaard, J.; Poulsen, R.N.; Christensen, S. Are vegetation indices derived from consumer-grade cameras mounted on UAVs sufficiently reliable for assessing experimental plots? Eur. J. Agron. 2016, 74, 75-92. [CrossRef]

48. Holman, F.H.; Riche, A.B.; Michalski, A.; Castle, M.; Wooster, M.J.; Hawkesford, M.J. High throughput field phenotyping of wheat plant height and growth rate in field plot trials using UAV based remote sensing. Remote Sens. 2016, 8, 1031. [CrossRef]

49. Xue, J.; Su, B. Significant remote sensing vegetation indices: A review of developments and applications. J. Sens. 2017, 2017, 1353691. [CrossRef]

50. Khan, Z.; Rahimi-Eichi, V.; Haefele, S.; Garnett, T.; Miklavcic, S.J. Estimation of vegetation indices for high-throughput phenotyping of wheat using aerial imaging. Plant Methods 2018, 14, 20. [CrossRef] [PubMed]

51. Boken, V.K.; Shaykewich, C.F. Improving an operational wheat yield model using phenological phase-based Normalized Difference Vegetation Index. Int. J. Remote Sens. 2002, 23, 4155-4168. [CrossRef]

52. Gitelson, A.A.; Peng, Y.; Huemmrich, K.F. Relationship between fraction of radiation absorbed by photosynthesizing maize and soybean canopies and NDVI from remotely sensed data taken at close range and from MODIS $250 \mathrm{~m}$ resolution data. Remote Sens. Environ. 2014, 147, 108-120. [CrossRef] 
53. Haboudane, D.; Miller, J.R.; Tremblay, N.; Zarco-Tejada, P.J.; Dextraze, L. Integrated narrow-band vegetation indices for prediction of crop chlorophyll content for application to precision agriculture. Remote Sens. Environ. 2002, 81, 416-426. [CrossRef]

54. Raper, T.; Varco, J. Canopy-scale wavelength and vegetative index sensitivities to cotton growth parameters and nitrogen status. Precis. Agric. 2015, 16, 62-76. [CrossRef]

55. Vincini, M.; Frazzi, E. Comparing narrow and broad-band vegetation indices to estimate leaf chlorophyll content in planophile crop canopies. Precis. Agric. 2011, 12, 334-344. [CrossRef]

56. Ustuner, M.; Sanli, F.B.; Abdikan, S.; Esetlili, M.; Kurucu, Y. Crop type classification using vegetation indices of rapideye imagery. Int. Arch. Photogramm. Remote Sens. Spat. Inf. Sci. 2014, 40, 195. [CrossRef]

57. Abdel-Rahman, E.M.; Ahmed, F.B.; Ismail, R. Random forest regression and spectral band selection for estimating sugarcane leaf nitrogen concentration using EO-1 Hyperion hyperspectral data. Int. J. Remote Sens. 2013, 34, 712-728. [CrossRef]

58. Han, L.; Yang, G.; Dai, H.; Xu, B.; Yang, H.; Feng, H.; Li, Z.; Yang, X. Modeling maize above-ground biomass based on machine learning approaches using UAV remote-sensing data. Plant Methods 2019, 15, 10. [CrossRef] [PubMed]

59. Hassanijalilian, O.; Igathinathane, C.; Doetkott, C.; Bajwa, S.; Nowatzki, J.; Esmaeili, S.A.H. Chlorophyll estimation in soybean leaves infield with smartphone digital imaging and machine learning. Comput. Electron. Agric. 2020, 174, 105433. [CrossRef]

60. Guo, Y.; Yin, G.; Sun, H.; Wang, H.; Chen, S.; Senthilnath, J.; Wang, J.; Fu, Y. Scaling Effects on Chlorophyll Content Estimations with RGB Camera Mounted on a UAV Platform Using Machine-Learning Methods. Sensors 2020, 20, 5130. [CrossRef]

61. Yao, D.; Yang, J.; Zhan, X. An improved random forest algorithm for class-imbalanced data classification and its application in PAD risk factors analysis. Open Electr. Electron. Eng. J. 2013, 7, 62-70. [CrossRef]

62. Ramos, A.P.M.; Osco, L.P.; Furuya, D.E.G.; Gonçalves, W.N.; Santana, D.C.; Teodoro, L.P.R.; da Silva Junior, C.A.; Capristo-Silva, G.F.; Li, J.; Baio, F.H.R. A random forest ranking approach to predict yield in maize with uav-based vegetation spectral indices. Comput. Electron. Agric. 2020, 178, 105791. [CrossRef]

63. Cakir, R. Effect of water stress at different development stages on vegetative and reproductive growth of corn. Field Crops Res. 2004, 89, 1-16. [CrossRef]

64. Zhao, X.; Tong, C.; Pang, X.; Wang, Z.; Guo, Y.; Du, F.; Wu, R. Functional mapping of ontogeny in flowering plants. Brief. Bioinform. 2012, 13, 317-328. [CrossRef]

65. Du Plessis, J. Maize Production; Department of Agriculture Pretoria: Pretoria, South Africa, 2003.

66. Uddling, J.; Gelang-Alfredsson, J.; Piikki, K.; Pleijel, H. Evaluating the relationship between leaf chlorophyll concentration and SPAD-502 chlorophyll meter readings. Photosynth. Res. 2007, 91, 37-46. [CrossRef] [PubMed]

67. Costa, C.; Frigon, D.; Dutilleul, P.; Dwyer, L.M.; Pillar, V.D.; Stewart, D.W.; Smith, D.L. Sample size determination for chlorophyll meter readings on maize hybrids with a broad range of canopy types. J. Plant Nutr. 2003, 26, 1117-1130. [CrossRef]

68. Markwell, J.; Osterman, J.C.; Mitchell, J.L. Calibration of the Minolta SPAD-502 leaf chlorophyll meter. Photosynth. Res. 1995, 46, 467-472. [CrossRef]

69. Ling, Q.; Huang, W.; Jarvis, P. Use of a SPAD-502 meter to measure leaf chlorophyll concentration in Arabidopsis thaliana. Photosynth. Res. 2011, 107, 209-214. [CrossRef]

70. Hutton, J.; Lipa, G.; Baustian, D.; Sulik, J.; Bruce, R. High Accuracy Direct Georeferencing of the Altum Multi-Spectral Uav Camera and its Application to High Throughput Plant Phenotyping. Int. Arch. Photogramm. Remote Sens. Spat. Inf. Sci. 2020, 43, 451-456. [CrossRef]

71. Zhang, F.; Zhou, G. Estimation of canopy water content by means of hyperspectral indices based on drought stress gradient experiments of maize in the north plain China. Remote Sens. 2015, 7, 15203-15223. [CrossRef]

72. Naito, H.; Ogawa, S.; Valencia, M.O.; Mohri, H.; Urano, Y.; Hosoi, F.; Shimizu, Y.; Chavez, A.L.; Ishitani, M.; Selvaraj, M.G. Estimating rice yield related traits and quantitative trait loci analysis under different nitrogen treatments using a simple towerbased field phenotyping system with modified single-lens reflex cameras. ISPRS J. Photogramm. Remote Sens. 2017, 125, 50-62. [CrossRef]

73. Haghighian, F.; Yousefi, S.; Keesstra, S. Identifying tree health using sentinel-2 images: A case study on Tortrix viridana L. infected oak trees in Western Iran. Geocarto Int. 2020, 37, 304-314. [CrossRef]

74. Qiu, Z.; Xiang, H.; Ma, F.; Du, C. Qualifications of rice growth indicators optimized at different growth stages using unmanned aerial vehicle digital imagery. Remote Sens. 2020, 12, 3228. [CrossRef]

75. Fitzgerald, G.; Rodriguez, D.; O'Leary, G. Measuring and predicting canopy nitrogen nutrition in wheat using a spectral index-The canopy chlorophyll content index (CCCI). Field Crops Res. 2010, 116, 318-324. [CrossRef]

76. Wu, C.; Niu, Z.; Tang, Q.; Huang, W. Estimating chlorophyll content from hyperspectral vegetation indices: Modeling and validation. Agric. For. Meteorol. 2008, 148, 1230-1241. [CrossRef]

77. Dye, M.; Mutanga, O.; Ismail, R. Examining the utility of random forest and AISA Eagle hyperspectral image data to predict Pinus patula age in KwaZulu-Natal, South Africa. Geocarto Int. 2011, 26, 275-289. [CrossRef]

78. Luan, J.; Zhang, C.; Xu, B.; Xue, Y.; Ren, Y. The predictive performances of random forest models with limited sample size and different species traits. Fish. Res. 2020, 227, 105534. [CrossRef]

79. Adam, E.; Mutanga, O.; Rugege, D.; Ismail, R. Discriminating the papyrus vegetation (Cyperus papyrus L.) and its co-existent species using random forest and hyperspectral data resampled to HYMAP. Int. J. Remote Sens. 2012, 33, 552-569. [CrossRef]

80. Sibanda, M.; Onisimo, M.; Dube, T.; Mabhaudhi, T. Quantitative assessment of grassland foliar moisture parameters as an inference on rangeland condition in the mesic rangelands of southern Africa. Int. J. Remote Sens. 2021, 42, 1474-1491. [CrossRef] 
81. Taghizadeh-Mehrjardi, R.; Mahdianpari, M.; Mohammadimanesh, F.; Behrens, T.; Toomanian, N.; Scholten, T.; Schmidt, K. Multi-task convolutional neural networks outperformed random forest for mapping soil particle size fractions in central Iran. Geoderma 2020, 376, 114552. [CrossRef]

82. Clevers, J.G.; Gitelson, A.A. Remote estimation of crop and grass chlorophyll and nitrogen content using red-edge bands on Sentinel-2 and-3. Int. J. Appl. Earth Obs. Geoinf. 2013, 23, 344-351. [CrossRef]

83. Broge, N.H.; Leblanc, E. Comparing prediction power and stability of broadband and hyperspectral vegetation indices for estimation of green leaf area index and canopy chlorophyll density. Remote Sens. Environ. 2001, 76, 156-172. [CrossRef]

84. Sankaran, S.; Maja, J.M.; Buchanon, S.; Ehsani, R. Huanglongbing (citrus greening) detection using visible, near infrared and thermal imaging techniques. Sensors 2013, 13, 2117-2130. [CrossRef]

85. Singhal, G.; Bansod, B.; Mathew, L.; Goswami, J.; Choudhury, B.; Raju, P. Chlorophyll estimation using multi-spectral unmanned aerial system based on machine learning techniques. Remote Sens. Appl. Soc. Environ. 2019, 15, 100235. [CrossRef]

86. Goodbody, T.R.; Tompalski, P.; Coops, N.C.; Hopkinson, C.; Treitz, P.; van Ewijk, K. Forest inventory and diversity attribute modelling using structural and intensity metrics from multi-spectral airborne laser scanning data. Remote Sens. 2020, 12, 2109. [CrossRef]

87. Curran, P.J.; Dungan, J.L.; Gholz, H.L. Exploring the relationship between reflectance red edge and chlorophyll content in slash pine. Tree Physiol. 1990, 7, 33-48. [CrossRef] [PubMed]

88. Nigam, R.; Tripathy, R.; Dutta, S.; Bhagia, N.; Nagori, R.; Chandrasekar, K.; Kot, R.; Bhattacharya, B.K.; Ustin, S. Crop type discrimination and health assessment using hyperspectral imaging. Curr. Sci. 2019, 116, 1108. [CrossRef]

89. Wu, B.; Ye, H.; Huang, W.; Wang, H.; Luo, P.; Ren, Y.; Kong, W. Monitoring the Vertical Distribution of Maize Canopy Chlorophyll Content Based on Multi-Angular Spectral Data. Remote Sens. 2021, 13, 987. [CrossRef]

90. Shanahan, J.F.; Schepers, J.S.; Francis, D.D.; Varvel, G.E.; Wilhelm, W.W.; Tringe, J.M.; Schlemmer, M.R.; Major, D.J. Use of remote-sensing imagery to estimate corn grain yield. Agron. J. 2001, 93, 583-589. [CrossRef]

91. Gitelson, A.A.; Kaufman, Y.J.; Merzlyak, M.N. Use of a green channel in remote sensing of global vegetation from EOS-MODIS Remote Sens. Environ. 1996, 58, 289-298. [CrossRef]

92. Rostami, M.; Koocheki, A.R.; Mahallati, M.N.; Kafi, M. Evaluation of chlorophyll meter (SPAD) data for prediction of nitrogen status in corn (Zea mays L.). Am.-Eurasian J. Agric. Sci. 2008, 3, 79-85.

93. Walker, B.J.; Drewry, D.T.; Slattery, R.A.; VanLoocke, A.; Cho, Y.B.; Ort, D.R. Chlorophyll can be reduced in crop canopies with little penalty to photosynthesis. Plant Physiol. 2018, 176, 1215-1232. [CrossRef]

94. Dahms, T.; Seissiger, S.; Conrad, C.; Borg, E. Modelling biophysical parameters of maize using landsat 8 time series. Int. Arch. Photogramm. Remote Sens. Spat. Inf. Sci. 2016, 41, 171-175. [CrossRef]

95. Costa, C.; Dwyer, L.M.; Dutilleul, P.; Stewart, D.W.; Ma, B.L.; Smith, D.L. Inter-relationships of applied nitrogen, SPAD, and yield of leafy and non-leafy maize genotypes. J. Plant Nutr. 2001, 24, 1173-1194. [CrossRef]

96. Mutanga, O.; Adam, E.; Cho, M.A. High density biomass estimation for wetland vegetation using WorldView-2 imagery and random forest regression algorithm. Int. J. Appl. Earth Obs. Geoinf. 2012, 18, 399-406. [CrossRef] 